ESSAY REVIEW

\title{
Scientocracy: Why a Science Court Is Needed
}

\section{Scientocracy: The Tangled Web of Public Science and Public} Policy edited by Patrick J. Michaels and Terence Kealey. Cato Institute, 2019. 368 pp. \$19.95 (paperback). ISBN 978-1948647496.

\section{Reviewed by Henry H. Bauer}

Virginia Polytechnic Institute \& State University

hhbauer@vt.edu www.henryhbauer.homestead.com

https://doi.org/10.31275/20201745

Creative Commons License CC-BY-NC

The Introduction is spot on: "Science can be a force for good, and it has enhanced our lives in countless ways, but even a cursory look at the $20^{\text {th }}$ century shows that what passes for science can be detrimental" (p. 1).

Ten of the eleven chapters of this book are comprehensively documented case studies demonstrating in each instance that the pertinent public policies were based on or justified by supposedly scientific understanding when in reality the so-called science was quite inadequate to support those policies; and moreover was severely biased by conflicts of interest and vested interests of the panels and advisory committees given the responsibility for assessing the actual state of the relevant scientific knowledge. These case studies are valuable, including as resources for other scholars, and it is regrettable that much of the book would have benefited from better copyediting; for instance, on page 55, "life expectancies ... have continued to rise . . . by three months for every year lived"-what does that mean? The reference (\#48) given as source doesn't help because its URL link doesn't work. And it is also not helpful to learn that "Western diet had the dual effect of both stimulating and damaging our health" (p. 55), particularly since the cited reference (\#49) says nothing about "Western diet". It is also 
annoying that the figures are too small, and that the colors relied on for making distinctions are too faint and indistinct in several figures.

The book does illustrate quite convincingly that the nature of contemporary scientific activity is nothing like the traditional, conventional view of science as a disinterested activity delivering public goods. As discussed in comprehensive detail in Science Is Not What You Think (Bauer, 2017a), among the salient factors for this difference are the rat race for obtaining funds for research and the fact that peer review serves only to entrench whatever the consensus is among the dominant cliques in each scientific specialty.

Chapter 1 of the book is colored by the Cato Institute's libertarian ideology, seeking to make government funding of research the culprit for the dysfunctional state of affairs; and that view is parroted to some extent in various ways in later chapters. The argument is made by data indicating that governmental funding of research did not increase national GNP per capita (p. 26). But that is not an appropriate measure of what is good for the population as a whole. GNP in the US, for example, would be lower if the healthcare system cost less while delivering better health outcomes, as is the case in Canada, Australia, and many European countries where government manages healthcare more directly and firmly.

Although it is certainly true that the corruption of scientific activity began to increase when government funding for research increased enormously, namely after the end of World War II, government funding is not uniquely or primarily responsible for what is wrong with science nowadays. The fundamental problem is that so many areas of research now require more funding than individual universities are able or willing to supply. Researchers must therefore obtain resources through their own efforts, and the old saying is perfectly applicable: "Those who pay the piper, call the tunes." That is certainly true for industrial funding of academic research as much as it is for industrial funding of in-house research and as it is for funding by government agencies; indeed, it is true for much of the funding from private charitable foundations, which naturally and quite properly support research that is likely to promote the causes the foundations are set up to advance.

Chapter 1 is unusually good, however, in describing how science and technology are related (or not; see also pp. 161-162); and it is also 
unusually good in describing the many mis- and ab-uses of statistical analysis, one consequence being that fields relying on statistical analysis suffer pervasively from the currently deplored "crisis of (ir) reproducibility" (pp. 28-29).

Chapter 2 documents the sad story of misleading advice about risks allegedly associated with various forms of dietary fat. There is actually no convincing evidence that saturated fat in the diet is harmful, and it is simply wrong to claim that high blood levels of cholesterol (or one of its forms) cause cardiovascular problems (e.g., Ravnskov, 2000; Kendrick, 2008, 2014). It took 60 years for misguided official warnings against cholesterol-rich foods to cease, illustrating a common dysfunction (p. 45): Once official advice has been issued, even when based on inadequate evidence, it is a Herculean task to have it modified even as convincing evidence mounts; many practicing doctors continue to believe these falsehoods (p. 46). Figure 2.1 (p. 40) indicates that mortality from strokes is not caused by atherosclerotic heart disease since the incidences changed differently over the years (pp. 52, 53).

It irritates me greatly when a book gets simple arithmetic wrong. Chapter 2 states (p. 54) that the change from $2.6 \%$ to $6 \%$ is "more marked" than that from $13.4 \%$ to $30.9 \%$, yet in both cases the ratio is the same, 2.3076 and 2.3060 , to be pedantically accurate. Such careless innumeracy makes questionable everything in this chapter wherein data matter.

Chapter 3 demolishes the still-prevalent myth that public health would be served by restricting the intake of salt; and it describes how the system of committees and official agencies kept the myth hegemonic, with facts ignored or distorted; it was necessary only "to convince key government officials and the public" (p. 97). Blood pressure is a biomarker for salt intake, but that does not make it a valid measure of overall health outcomes (p. 107). Harmful misuse of biomarkers is widespread (Institute of Medicine, 2010, 2011).

Chapter 4 points out that hysteria over drug abuse has had the very harmful consequence of denying pain-alleviating medication to some who genuinely need such relief: There was no correlation between number of prescriptions written in a given region and the number of addicts there (p. 132 f.); indeed, all the popular beliefs about the opioid 
epidemic are wrong (p. 138). Data on potency ( $p$. 117) may be of general interest: heroin and methadone, 2.5 times as potent as morphine, hydromorphone about 6 times as potent as morphine, fentanyl 50 times as potent as morphine; while oral codeine is only $1 / 6$ as potent as morphine.

Chapter 5 describes how bu reaucratic entrenchment of beliefs about the great dangers of marijuana, psilocybin, LSD, and similar drugs has dysfunctionally prevented research that could well establish useful medical applications for these

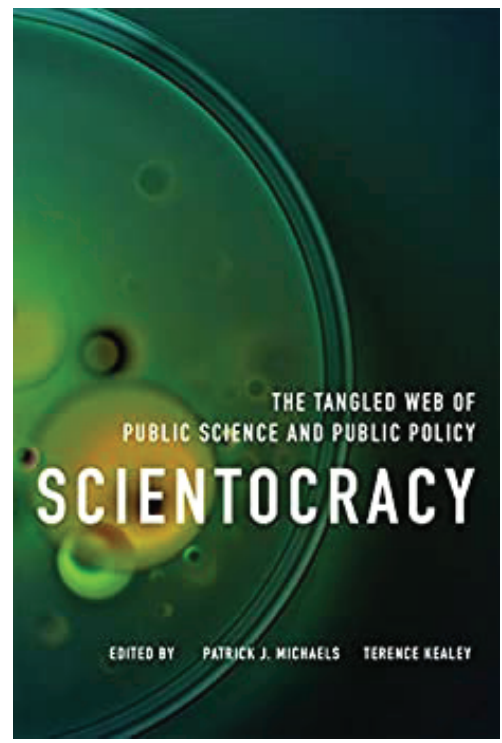
and related substances. "Ecstasy" (MDMA) had been patented in 1914 and used for a long time in psychotherapy (p. 153 ff.), with particular success in cases of PTSD (p. 159). Prohibition is no substitute for sensible regulation (p. 160).

Chapter 6 is a largely well-founded tirade deploring how bureaucracy, owing chiefly to government actions, works against useful medical innovation. But the libertarian bias for private as opposed to government funding is pervasively overt in this chapter, and contrary to actual experience with respect to academic research (p. 165); the bias goes so far as to describe as "reliable medical information" what drug representatives convey to doctors (pp. 179-180). The chapter is also seriously wrong on one very important point: in welcoming, as an example of desirable non-government-influenced medical innovation, the introduction of statin drugs (p. 168), which in reality cause demonstrable harm by weakening the body's energy-producing mechanisms (e.g., Langsjoen \& Langsjoen, 2008; Langsjoen et al., 2008; Hansen et al., 2005; Anonymous, 2010; de Lorgeril \& Rabaeus, 2015; Rabaeus et al., 2017) and whose supposed benefit is based on the mistaken view (Ravnskov, 2000; Kendrick, 2008, 2014) that high cholesterol levels in the blood constitute cardiovascular disease. The building up of plaque in the arteries is initiated by inflammation 
or physical damage, and some of the occasional benefit attributed to statins can be explained by their somewhat anti-inflammatory properties. That " 80 percent of ... drug approvals arose solely from ... private industry" (p. 167) reflects not service to public health but rather the marketing of me-too modifications and substances, like statins, of at-best-doubtful public benefit (Moore, 1995, 1998; Angell, 2004; Goozner, 2004; Moynihan \& Cassels, 2005; Brownlee, 2007; Greene, 2007; Petersen, 2009; Healy, 2012; Goldacre, 2013; Gøtzsche, 2013).

Chapter 7 demonstrates that official regulation of carcinogens and other chemicals is based on a fallacy, namely that the risk of harm is linearly proportional to the exposure dose. Amply documented is how this came about, in part through deliberate distortion of evidence by self-interested people and groups; and it illustrates once more how such a fallacy can persist for a long time-several generations of researchers and practitioners (p. 189). In reality, the pertinent data and evidence show beyond doubt that there is no harm below a certain threshold, or in many cases and even more strikingly that substances harmful at high doses may actually be beneficial at very low exposures. That phenomenon, hormesis, though perhaps surprising at first mention, has an entirely conventional and logical basis: The immune system detects potential harm and is activated beyond its normal resting state, with beneficial side effects. The author of this chapter, Edward Calabrese, is also the scientist whose work established hormesis as a general phenomenon, and his work has been supported by government funding (p. 207). This chapter alone is worth the price of the whole book.

Chapter 8 builds on the knowledge conveyed by chapter 7 to show how ignorance of hormesis with respect to exposure to radiation has been harmful in the long-drawn-out battle over whether to permit the mining of uranium in Virginia. Illustrated is that the National Research Council cannot be relied on for an accurate, impartial assessment.

Chapter 9 relates the continuing battle over potential mining of mineral deposits in Alaska. Here the salient factor is not so much bureaucratic reliance on faulty science as bureaucratic arrogance in abusing current legislation by even preempting scientific assessments.

Chapter 10 focuses on some aspects of the mistaken view that 
carbon dioxide is the primary and harmful cause of global warming; and it shows that the computer models on which all climate-change hysteria is based are simply wrong; they are "tuned" subjectively (p. 250), in other words rely on fudge factors. Focusing on highly technical details, this chapter could have been more readily accessible to most readers if it had also emphasized the actual historical data of periodic ice ages separated by much warmer periods, as well as the data comparing historical temperatures with contemporaneous levels of atmospheric carbon dioxide (Bauer, 2017b). Nevertheless, this is a clear demonstration that existing courts cannot deliver properly informed judgments when questions of disputed scientific understanding are at issue (p. 240).

Finally, chapter 11 details the excruciatingly bad statistics applied in the regulation of fine particulate matter in the atmosphere. This willfully ignorant and shockingly incompetent resort supposedly to statistical science applies also to earlier chapters. Almost all or perhaps even all of the dysfunctional official advice about nutrition in particular and health in general transgresses perhaps the most important single thing about statistical analysis; namely, that correlation or association is no proof of causation. Beyond that, the attempt to detect single causes for the effects of diet or of the environment seems wrongheaded a priori: Essentially innumerable possible influences exist and there is no satisfactory way to control for the possible influences of factors other than the one of specific interest in any given research. Given that the statistical analyses do not hold water, I wondered about animal studies of harm from inhalation of fine particulate matter and was disappointed to find no discussion of the host of existing studies.

This book demonstrates beyond any reasonable doubt that policymakers and regulating agencies cannot obtain impartial, disinterested, objective assessments of the state of scientific knowledge from existing sources. The National Academy of Sciences, the National Research Council, and all other scientific and academic organizations, be they national or international, private or public or governmental, inevitably reflect the prevailing scientific consensus, the conventional wisdom within the scientific community; and that is simply the opinions within the currently dominant clique. It is quite obviously impossible to obtain impartial, disinterested assessments from the 
putative experts in any given field since the conventional wisdom in that field is synonymous with the views of those experts.

Law-makers and policy-makers and regulators do, however, sorely need impartial, disinterested, objective assessments of the state of scientific knowledge on any matter pertinent to public policies. The suggestion (p. 59) that investigative journalists can deliver these goods is whistling in the wind, since their published findings have no power to force compliance with impartial fact. To deliver impartial, disinterested judgments and to enforce appropriate compliance on controversial matters, society developed the system in which courts supervised by disinterested judges allow opposing points of view to be presented and argued, under cross-examination and with the assistance of pertinent witnesses. The necessary decision is arrived at either by a single judge, or by a panel of judges, or by a jury of people selected without vested interest in the result. The same sort of arrangement, in the form of a specifically Science Court, seems to be the only conceivable way in which society could have the benefit of truly impartial assessments of contemporary scientific understanding.

The concept of a specifically Science Court dates back at least half a century. Kantrowitz (1967) suggested that an "Institute for Scientific Judgment" was needed as policymakers were being exposed to sharply differing scientific opinions about the potential safety of atomic reactors for generating power for general civilian use. Over the years, a number of discussions ensued about the concept, soon described as a Science Court. A further justification for such an Institution lies in the difficulties that the civil court system faces when matters of scientific knowledge and understanding are at issue, which the courts are simply not equipped to handle (Jurs, 2010); for instance, courts need to determine whether witnesses called as experts by opposing parties genuinely deserve to be regarded as expert, which implies impartial. Moreover, federal regulators and officials can ignore findings by a civil court on matters of scientific understanding, as happened with keeping marijuana as a Schedule 1 drug (pp. 144-145). The many points to be considered in the possible establishment of a Science Court have been discussed in the previously cited book by Bauer (2017a, Chapter 12). 


\section{References}

Angell, M. (2004). The truth about the drug companies: How they deceive us and what to do about it. Random House.

Anonymous. (2010, October 18). Do statins have a role in primary prevention? An update. Therapeutics Letter, 77. https:/www.ti.ubc.ca/2010/10/18/do-statinshave-a-role-in-primary-prevention-an-update/

Bauer, H. H. (2017a). Science is not what you think: How it has changed, why we can't trust it, how it can be fixed. McFarland.

Bauer, H. H. (2017b). Climate-change facts: Temperature is not determined by carbon dioxide. https://scimedskeptic.wordpress.com/2017/05/02/climatechange-facts-temperature-is-not-determined-by-carbon-dioxide

Brownlee, S. (2007). Overtreated: Why too much medicine is making us sicker and poorer. Bloomsbury.

de Lorgeril, M., \& Rabaeus, M. (2015). Beyond confusion and controversy, can we evaluate the real efficacy and safety of cholesterol-lowering with statins? Journal of Controversies in Biomedical Research, 1(1), 67-92. https://doi.org/10.15586/jcbmr.2015.11

Goldacre, B. (2013). Bad pharma: How drug companies mislead doctors and harm patients. Faber \& Faber.

Goozner, M. (2004). The $\$ 800$ million pill: The truth behind the cost of new drugs. University of California Press.

Gøtzsche, P. C. (2013). Deadly medicines and organised crime: How big pharma has corrupted healthcare. Radcliffe.

Greene, J. A. (2007). Prescribing by numbers: Drugs and the definition of disease. Johns Hopkins University Press.

Hansen K. E., Hildebrand, J. P., Ferguson, E. E., \& Stein, J. H. (2005). Outcomes in 45 patients with statin-associated myopathy. Archives of Internal Medicine, 165(22), 2671-2676. https://doi.org/10.1001/archinte.165.22.2671

Healy, D. (2012). Pharmageddon. University of California Press.

Institute of Medicine. (2010). Evaluation of biomarkers and surrogate endpoints in chronic disease edited by C. M. Micheel \& J. R. Ball. National Academies Press. https://doi.org/10.17226/12869

Institute of Medicine. (2011). Perspectives on biomarker and surrogate endpoint evaluation: Discussion forum summary. A. Mack, E. Balogh, \& C. Micheel, rapporteurs. National Academies Press. https://doi.org/10.17226/13038

Jurs, A. W. (2010). Science court: Past proposals, current considerations, and a suggested structure. Drake University Legal Studies Research Paper Series, Research Paper No. 11-06; Virginia Journal of Law and Technology 15(1). https://papers.ssrn.com/sol3/papers.cfm?abstract_id=1561724

Kantrowitz, A. (1967). Proposal for an institution for scientific judgment. Science, 156(3776), 763-764. https://doi.org/10.1126/science.156.3776.763

Kendrick, M. (2008). The great cholesterol con: The truth about what really causes heart 
disease and how to avoid it.. John Blake. [Updated from 2007 1st ed.]

Kendrick, M. (2014). Doctoring data: How to sort out medical advice from medical nonsense. Columbus Publishing.

Langsjoen, P. H., \& Langsjoen, A. M. (2008, December 16). The clinical use of HMG CoA-reductase inhibitors and the associated depletion of coenzyme Q10. A review of animal and human publications. BioFactors, 18, 101-111. https://doi.org/10.1002/biof.5520180212

Langsjoen, P. H., Langsjoen, J. O., Langsjoen, A. M., \& Lucas, L. A. (2008, December 19). Treatment of statin adverse effects with supplemental Coenzyme Q10 and statin drug discontinuation. BioFactors, 25, 147-152.

https://doi.org/10.1002/biof.5520250116

Moore, T. J. (1995). Deadly medicine: Why tens of thousands of heart patients died in America's worst drug disaster. Simon \& Schuster.

Moore, T. J. (1998). Prescription for disaster: The hidden dangers in your medicine cabinet. Simon \& Schuster.

Moynihan, R., \& Cassels, A. (2005). Selling sickness: How the world's biggest pharmaceutical companies are turning us all into patients. Nation Books.

Petersen, M. (2009). Our daily meds: How the pharmaceutical companies transformed themselves into slick marketing machines and hooked the nation on prescription drugs. Picador (Pan Macmillan).

Rabaeus, M., Nguyen, P. V., \& de Lorgeril, M. (2017). Recent flaws in evidencebased medicine: Statin effects in primary prevention and consequences of suspending the treatment. Journal of Controversies in Biomedical Research, 3(1), 1-10. https://doi.org/10.15586/jcbmr.2017.18

Ravnskov, U. (2000). The cholesterol myths. New Trends Publishing. 